\title{
Social Justice in Application: Counselor Training in a Legal Context
}

\author{
Krista M. Malott and Tacia Knoper \\ Villanova University
}

\begin{abstract}
A paradigm shift in counseling toward a social justice framework indicates the need for corresponding change in counselor education practices. In this article, the authors present a unique, interdisciplinary training program at one university, whereby counseling students aid clientele through social justice counseling in collaboration with students from the Law School and Modern Language Department. Program development and challenges unique to this collaborative venture are described. Three cases will illustrate the counselors' role in the context of legal practice.
\end{abstract}

Keywords. Social justice training, multicultural counseling, interdisciplinary training, legal advocacy

\section{Social Justice in Application: Counselor Training in a Legal Context}

A growing conviction that counselors' roles must include social justice advocacy has transformed the profession (Bemak, Chung, Talleyrand, Jones, \& Daquin, 2011; Chang, Crethar, \& Ratts, 2010; Lee, 2007; Ratts, Toporek, \& Lewis, 2010; Zalaquett, Foley, Tillotson, Dinsmore, \& Hof, 2008). Social justice entails the realization of a democratic community, wherein citizens have equitable access to resources and opportunities, and whose institutions are free of oppressive or hierarchical elements (Speight \& Vera, 2004). The social justice paradigm as applied to counseling suggests the use of advocacy and activism to increase equitable client access to resources and opportunities. In this paradigm, counselors collaborate with clients and various professionals to reduce contextual barriers that impede the personal, academic, and career advancement of clientele (Lewis, Ratts, Paladino, \& Toporek, 2011). 
Multicultural competency is interwoven across a social justice approach to client advocacy services. In such an approach, counselors must possess a critical awareness of their own and clients' world views and identity traits (e.g., gender, race, ethnicity, social class, etc.; Arredondo et al., 1996), as well as knowledge of personal biases and privileges associated with those factors. Effective multicultural counseling requires application of culturally-aligned intervention strategies, drawing upon clients' strengths and indigenous or cultural practices to promote client empowerment and advocate for societal change (D'Andrea \& Heckman, 2008; Green, McCollum, \& Hays, 2008).

The American Counseling Association (ACA) Advocacy Competencies (Lewis, Arnold, House, \& Toporek, 2003) identify three domains for counselor advocacy: client/student, school/community, and the public arena. Broadly, counselor advocacy activities seek to increase client dignity, reduce oppression or impediments to resources, and increase client access to resources. To effectively advocate for clients, counselors must possess various forms of knowledge related to self, others, and the systems around them. Foremost, they should understand the historical, social, and political oppression experienced by various groups of persons, as well as the effects of that oppression upon clients' mental health. Such knowledge includes ways the counseling profession itself can oppress or harm clients, including use of culturally incongruent counseling theories, assessments, diagnosis, or interventions. In relation to others, counselors should possess knowledge of culturally sensitive helping strategies, including collaborative skills and ways to draw upon client strengths and resources in advocating with, and empowering, clients (Counselors for Social Justice Ethics Committee, 2011).

In turn, counselor advocacy skills include actions that reduce barriers or obstacles that inhibit client success at individual, group, institutional, or societal levels (ACA Code of Ethics, 2005). Examples of specific skills may include, but are not limited to, the ability to: identify factors impeding client development in the system or manifested within that client (e.g., internalized oppression); develop and implement feasible advocacy action plans; identify and draw upon the clients' strengths, culture, and resources to co-design interventions; collaborate with clients and other professionals; communicate verbally and through written media to educate about, and ameliorate, oppressive situations; analyze situations, gather, assess, and disseminate pertinent data in an effort to advocate; negotiate, on behalf of clients, and; the ability to recognize and address resistance to change, as well as to assess the impact of counselor advocacy efforts (ACA Code of Ethics, 2005; Counselors for Social Justice Ethics Committee, 2011; Ratts, DeKruyf, \& Chen-Hayes, 2007).

Recent scholars have asserted the need to incorporate social justice advocacy training into counselor education programs (Bemak et al., 2011; Brubaker, Puig, Reese, \& Young, 2010; Murray, Pope, \& Rowell, 2010). Examples of such efforts in counselor education include student engagement in political activism (Murry et al., 2010), action-oriented research, and service work in collaboration with grassroots advocacy organizations to aid disenfranchised populations such as the homeless, refugees, and survivors of natural and manmade disasters (Bemak et al., 2011; Chung, Bemak, \& Grabosky, 2011; Vera \& Speight, 2007). Talleyrand, Chung and Bemak (2006) described an exemplar model of social justice training at one university setting, whereby social justice was woven into the foundation of the counselor education program itself, informing the mission statement, hiring practices, and course curriculum. Course content was 
premised upon social justice and multicultural competencies, and a new course was created to facilitate actual student engagement in social justice advocacy practices.

Empirical and anecdotal evidence suggests such educational experiences to be highly meaningful for students, expanding their skills in multicultural sensitivity and client advocacy (Nilsson, Schale, \& Khamphakdy-Brown, 2011) and increasing the likelihood of later engagement with social justice issues (Bemak et al., 2011; Eyler, Giles, \& Schmiede, 1996; Furco \& Billig, 2002; Green et al., 2008). In turn, experts have recognized social justice field experiences, in conjunction with interdisciplinary collaboration, as key transformative components of counselor preparatory programs (Barrett, 2011; Chang et al., 2010; Dixon, Tucker, \& Clark, 2010; Vera \& Speight, 2007).

However, in spite of myriad and pressing calls for social justice counselor training, there is a paucity of specific educational models in the literature. Limited guidelines render the creation of actual field experiences difficult for faculty members who may already experience anxiety related to novice training approaches (Ratts \& Wood, 2011). In an effort to provide an example of one social justice advocacy training model, the authors present a unique interdisciplinary training program, whereby student counselors aid clients in a legal context. Following is a description of the program as it developed over time, with suggestions for adaptation of the model to additional educational or clinical settings.

\section{Program Collaborators}

In this interdisciplinary venture, housed at a small, private university, master-level counseling students support underserved clients in conjunction with law students (e.g., post graduate, or professional, students) and, when necessary, through the aid of interpreters who are undergraduate students studying a foreign language. Four Law Clinics, housed within the University's Law School, offer the lawyers-in-training client and court experience as well as an opportunity for supervision and training in social justice advocacy across diverse populations. Each clinic offers pro-bono legal advocacy for underrepresented clients in one of four areas: monetary/tax controversies with the Internal Revenue Service; a wide array of civil disputes; farm workers' rights; and, asylum, refugee and emigrant services.

Within the general Law School, students receive training that pertains to knowledge building of the Anglo-American common law tradition, as well as mastery of federal and state statutory and administrative regimes. In their final year of schooling, they may apply for a semester-long position at one of the four clinics. As students at the clinic, law students receive training and supervision regarding court preparation and client representation in a court setting. In addition, they learn effective collaborative practices with student counselors and interpreters, as well as skill building for client interviewing (or what could be considered basic counseling skills). Similarly, undergraduate students from the university's Modern Languages Department gain valuable work experience and receive course credit by acting as interpreters for clinic cases. Their main tasks include interpretation of sessions between the clients, counselors, and law students, and translation of various documents for use in court. They receive ongoing training and supervision from faculty members in the Modern Language's program in conjunction with the Law Clinic directors. 


\section{Program Initiation}

Initiation of the Counselor-Law Collaborative began with a chance meeting between a Law Clinic director and the first author, who is a faculty member in the master-level counselor training program at the same university. Frequently, the first step for faculty members in interdisciplinary work is self-education regarding the other's profession, as well as of the practice of interdisciplinary teaching itself (Lattuca, 2002). This was particularly true for all four Law Clinic directors who, in spite of the fact that collaboration between social workers and lawyers is fairly common (Golick \& Lessem, 2004), professed limited understanding of a counselor's potential role in aiding legal practices.

Drawing from the literature regarding social worker-law collaboratives, Galowitz (1999) offered a compelling argument for the development of counseling-law collaboration. In her article, she cited mental health professionals as "better equipped than lawyers to provide services such as crisis intervention, evaluation of clients' needs, referrals to appropriate agencies" (pp. 2126), asserting that social workers' training in assessing personality and mental status will significantly contribute to how a lawyer will appraise the case. In addition, mental health specialists in a legal context can provide unique assistance that includes advocacy, work with community groups, community development, and preventative education. Finally, Galowitz (1999) noted that "a very significant though frequently overlooked reason for collaboration is to help share and ease the lawyer's burden. [Mental health specialists] can help lawyers deal with their feelings about their clients and their practice" (p. 2128).

Consequently, to facilitate collaboration across programs, the first author approached the clinic directors with a description of potential services counselors could offer to their clinics (Appendix A). That handout, which has evolved over time and through experience, continues to be used each semester to educate law students regarding student-counselors' role in the collaborative. Conversely, the first author initially sought to educate herself regarding the Law Clinics and general interdisciplinary practices with literature regarding social worker-lawyer collaboratives (e.g., Anderson, Barenberg, \& Tremblay, 2006; Galowitz, 1999; Maidenberg \& Golick, 2001) while also attending lectures and events (e.g., guest speakers; workshops) offered by the Clinic directors. Incorporation of student counselors into the clinic setting was a gradual development, from assigning two graduate assistants to the project in its first year, as a pilot program, to recruitment of interested counseling students for multiple years following, to eventual inclusion of the project within a multicultural counseling course.

\section{Counselor Training and Supervision}

Currently, the Counselor-Law Collaborative is incorporated as a 'field' component within a required multicultural counseling course. The master's-level counseling students can take the course at any stage in their training. Major course goals include expanding students' multicultural competencies and skills and knowledge in social justice advocacy practices. Initially, the instructor creates a knowledge base for advocacy through introduction of a critical Whiteness framework (Hitchcock, 2002). That framework is identified as an overarching set of cultural norms and practices that comprise various sociocultural, political, and educational systems (including the discipline of counseling). The mental health impact of that culture upon individual clientele is examined through the literature and various lectures and videos. 
Subsequent course pedagogy focuses on expanding counselors' awareness of their own world views, privileges, and potential biases.

Skills specific to social justice advocacy are interwoven across the lectures, as well as applied and practiced through various case studies and during the field component of the course (Lewis et al., 2003). Outside of the classroom time, students meet bi-weekly with the course instructor to develop and apply skills with actual clients that come to them through the Counselor-Law Collaborative. Examples of specific skill development during supervision sessions include initial student practice in identifying the role of context on a client's presenting issue. They are asked to draw upon clients' unique barriers, strengths, resources, and indigenous healing practices to determine clinical interventions (Godźiak, 2004; Smith, 2006), as well as to propose solutions to common problems in collaborative practices. At that time, they may also recognize the need for individual or systemic advocacy, and they will be asked to consider various avenues for intervention, including empowerment of the client to advocate on his or her behalf. Finally, they will develop a plan of action for collaboration with the client and various allies (e.g., law students and other professionals) in order to most effectively apply an intervention.

Consequently, training and supervisory goals of the collaborative portion of the course include development of student-counselors' awareness, knowledge, and skills regarding (a) social justice advocacy, (b) interdisciplinary collaboration, and (c) multicultural counseling. The Discrimination Model (Bernard, 1997) of supervision is applied with students, wherein supervisory responses are tailored to meet students' developmental needs. In such a model, there is a focus in three skill areas: the counselor's intervention (e.g., what the counselor is doing with the client), client conceptualization (how the counselor perceives what is occurring with the client), and personalization (how the counselor's own personhood - personal style, beliefs, and issues - interfaces with the counseling process).

Social justice advocacy supervision (Glosoff \& Durham, 2010) is interwoven across this process. This entails the use of focused discussions and reflective questioning to expand counselors' awareness of self (sociocultural traits such as gender, religion, culture, race, nationality, including their intersection with privilege and oppression), critical thinking skills, cognitive complexity, and consciousness regarding diversity issues. In turn, increased critical consciousness promotes the counselors' understanding of the need for client advocacy (Borders \& Brown, 2005; Glosoff \& Durham, 2010).

During initial supervision sessions, procedures for establishing and maintaining interdisciplinary contact are also introduced (Galowitz, 1999; Wright, 2005). Three possible ways to support clients exist. In the first option, counselors work as a team member alongside the law students in tasks such as preparing and rehearsing for court hearings, or interviewing clients regarding their past histories. A second option allows the counselor and client to work separately from the lawyers. In this scenario, the counselor seeks to meet the client's and law students' stated goals, regularly updating the law students and clinic directors on general goal progress via written reports. With this second option, the client is informed that the counselor is a member of the legal team and that he or she may need to share new information learned about the case with the law students (with the client's permission). The third option in aiding clients is to provide client services after the legal case has been closed. In this instance, the law students are not involved, although progress notes will be stored at both the Counseling Department and Law Clinic (Galowitz, 1999; Wright, 2005). 
Finally, additional counseling supervision is provided every other week at the Law Clinic, overseen by a clinic staff member who is a paralegal. In that setting, discussion primarily focuses on the legal aspects of cases. Law students and clinic directors frequent those sessions to discuss client issues, seek consultation regarding new cases, and to offer formal and informal training on legal issues, policies, and practices. Over the course of the semester, as a connection forms across disciplines, counseling students are occasionally asked to participate in additional trainings (e.g., human trafficking, the asylum-seeking process, effective work with interpreters) and they have periodically been invited to engage in political advocacy efforts alongside law students.

\section{Counselor Commitment and Tasks}

During their semester working with the Counselor-Law Collaborative, the counseling students are required to commit at least one hour per week for supervision and to assume responsibility for at least one client case. Time commitment for cases can vary widely, from as little as one hour (such as providing a single referral service) to ongoing counseling and advocacy that can require as much as 20 hours of work. Common counselor tasks include basic counseling (identifying clients' strengths and indigenous practices to cope with stress or improve relationships), helping clients locate and access resources, advocating for or with clients to address barriers to accessing support services, helping clients prepare for court, and attending court hearings to provide client support.

To more equitably distribute students' time applied to cases, multiple counselors work together in aiding complex clients. In addition, an attempt is made to assign student counselors to cases that align with their developmental status. For instance, those who are further along in the counselor training program will be assigned cases that require more intensive clinical work. To promote learning across counseling students with different training, advocacy, and crosscultural experiences, all are asked to contribute to the cases during group supervision. In turn, course lectures, discussions, and assignments are designed to inform supervision and counseling sessions.

The clients are referred to the Law Clinic by various organizations or professionals across the nation, with examples including: Immigration Equality, Immigration and Customs Enforcement (ICE), Local Courts of Common Pleas, Hebrew Immigrant Aid Society, Legal Assistance Advocacy Programs, The Farmworker Law Project, and private attorneys. Of the approximately 250 clients who receive services through the Law Clinics each academic year, an average of 40 of those individuals will also receive assistance from student counselors.

Consequently, law students who notice any unmet mental health or basic needs of their clients may present counseling as an option, either during or after the actual case is tried in court. They will introduce the counselors as members of the legal team who are trained to attend to clients' basic, emotional, or relational needs. If the client expresses interest, the law students then complete and fax a referral form to the Counseling Department. The counseling supervisor, in conjunction with the students, then discusses and assigns the case to one or more counselors. 
Counseling tasks vary across cases and are determined by the goals set forth by two entitiesthe client and the law students. Initially, after a case is assigned, the designated counselor will consult with the law students, to explore their perception of the client's needs and to ascertain any confounding case variables, such as the legal status of clientele. For example, refugee clients who are homeless and jobless may be prohibited by the government to access employment or receive public health or mental health services. Conversely, clients who are citizens may be denied access to certain public resources (such as government monies to attend college) due to legal issues, such as outstanding debt. Following consult with the legal team to determine if any such issues are present, the counselor then meets with the client, at a location preferred by that client, to develop a working alliance and to verify the client's goals.

Client and law students' goals may differ slightly. For instance, the goals of law students are frequently related to case-specific needs. Common examples include helping a client find transportation to court-required services or law-school sessions, identifying professionals who can provide a pro-bono service that will inform the case (such as a doctor who will perform a medical examination to be used at the hearing), increasing client comfort in discussing his or her history, and preparing the client for court. Less common (approximately three to four clients per year) are crisis issues, with client expression of suicidality or feelings of depression related to trauma. Conversely, goals that are frequently identified by clients include assistance with career and educational counseling, improving personal relationships, coping skills related to past traumas or current discrimination, and support in identifying and physically accessing resources (for instance, learning how to use a bus system, for recently arrived immigrants).

At times, the counselors may never physically meet with clients, instead conversing with them via phone or, even, through the law students. In such instances, they are called upon to provide referrals to external services, such as counseling specialists (usually trauma), health care, or organizations that offer basic needs (clothing, housing, etc.). At other times, they may meet with a client on a weekly basis throughout the semester, with or without the law students. Meeting locations will vary according to client's preferences and access to transportation.

Of the approximately 40 clients presented to the counselors each year, approximately 6 to 7 of those persons may eventually drop out or decline certain services. This is particularly true for homeless clients who move frequently. Services most commonly declined by clients are those suggested by the lawyers. For instance, in custody cases, many of the law students recommend counseling for the client and related family members, to demonstrate to a judge the client's commitment to effective parenting. However, the majority of those clients choose not to make use of such services. Consequently, such experiences increase counselors' understanding of the importance of client goal setting in relation to motivation, as well as expanding skills for negotiating differing (and sometimes conflicted) preferences of collaborating professionals.

While working with clients, the need for advocacy often emerges. Examples from past cases include counselor advocacy with a client in addressing discrimination from a governmental agency that serves people with physical disabilities; advocating that a child client, who was being asked to testify in court before his alleged sexual abuser, be allowed to testify from a private room; and, educating a law student regarding the possible harmful effects of his stance toward an intersex (e.g., a person possessing male and female genitalia) client. 
Finally, the counselors also provide direct services as needed to the lawyers. In such instances, the lawyers may seek consult with the entire team of counselors regarding respectful or effective ways to interview clients (e.g., in an effort to minimize harm of clients who have experienced traumas, or to elicit case details with less verbal clients, such as children). In a recent example of this, a Law Clinic director and her students met with the student counselors to explore ways to broach the sensitive topic of sexual abuse through an interpreter and over the phone with an out-of-state client. Law students have also approached the counseling team seeking support or advice in coping with clients' trauma stories. At other times, they have consulted with the counseling team in an effort to gain an alternative perspective on a complex case.

\section{Case Examples}

The following narrative describes specific cases, to illustrate actual tasks executed by student counselors in the Counselor-Law Collaborative. Each case presents a client from a different Law Clinic. To protect client identities, names and certain details have been slightly altered.

\section{Farm Worker Clinic}

Monica, a Mexican immigrant, was referred to the counseling team following the closing of her legal case which had addressed work-related exploitation. Monica and her two adolescent children were monolingual Spanish speakers in need of shelter and multiple educational and basic support services. The counselors sought to develop Monica's skills and knowledge in navigating the various systems in their new country, including the housing, transportation, and educational systems. They provided her with myriad basic resources and empowered her to advocate for additional language-assistance for her children in the school system. They accompanied her to certain social service agencies she had experienced as discriminatory in prior visits. Regarding the clinical aspects of the work, the counselor addressed familial conflict between Monica and her partner. In addition, she received basic vocational support as guided by Blustein's (2006) psychology-of-working perspective, with a focus on empowerment in overcoming barriers to work, and efforts to expand work-related skills by connecting her with a vocational training program.

\section{Tax Clinic}

Ronald, a client at the tax clinic due to a serious debt problem, requested counseling support in managing debt-related anxiety, as well as financial counseling and relational support to address his conflicted relationship with his adult son. The counselor was able to locate free financial counseling available to older adults. She also drew upon Ronald's supports, resources, and strengths to facilitate coping with financial anxiety and family conflict. Ronald asked that the counselor be present in one particular meeting with the lawyers, to lend support as he revealed the true status of his monetary issues to his son. In that and subsequent sessions, the counselor was able to provide basic educational and relational counseling that expanded Ronald's life options and facilitated an unexpected familial reconciliation. 


\section{Asylee Clinic}

Evelyn and her family were French-speaking Africans who awaited a trial for asylum in a local detention center. Initial work with Evelyn, in conjunction with a French-speaking interpreter, was clinical in nature. Together they developed culturally congruent coping techniques to manage issues of trauma, loss and displacement so common to refugees (Prendes-Lintel, 2001). The counselor educated Evelyn and her husband on torture-related symptoms, and explained the need for specific health care for sexual assault survivors. Addressing immediate safety concerns, the counselor empowered Evelyn to advocate against mistreatment from detention-center guards that she perceived as racist in nature. Across that process, the law students separately sought support from the counselors in personally managing Evelyn's trauma story, as well as to expand their interview skills to better obtain details of Evelyn's past experience for use in court. In addition to clinical and consultation work, the counseling team obtained clothing donations so that Evelyn and her family could attend court in professional attire (thereby increasing their chances of success). To add credibility to the court case, a psychologist was recruited to evaluate Evelyn and compose an affidavit. Lastly, the counselor attended court with Evelyn, to aid her in coping with the retelling of her story; which, ultimately, had a successful outcome.

\section{Challenges}

Legal-mental health interdisciplinary work can present challenges profound enough to disrupt program effectiveness (Galowitz, 1999). A team consisting of the Law Clinic and Counseling directors, the paralegal, and various law and counseling students, meet annually to address challenges and suggest solutions. Following are the principal issues identified, as supported by experts regarding legal-mental health collaboratives.

\section{Confidentiality}

The greatest ethical concern of the collaboration involved differing standards of confidentiality related to client issues (Anderson et al., 2006). This conflict lies in differing ethical responsibilities toward clients, as "the lawyer's responsibility is to advocate zealously for the client's wishes, while the social worker's is to safeguard the client's best interests" (Galowitz, 1999, p. 2140). Through counsel with the legal representative for the American Counseling Association, it was determined that no binding rule existed regarding cross-disciplinary training.

The closest model was located in the literature addressing social work-legal collaboratives. In examining various social-worker-lawyer collaborative models, Galowitz (1999) found that some programs required that social worker students be bound by attorney-client rules of confidentiality when employed beneath a law firm. She observed, however, that other collaborative programs took the stance that social work students are mandated reporters, regardless of their employers. In addressing the issue, Anderson and colleagues (2006) concluded, "It remains an open question whether a social worker who does not report suspected abuse, but acts on a legal opinion from his law firm colleagues, has committed a criminal act" (p. 17).

In response to that literature, it was determined that counseling students would honor the counselor's rules of confidentiality in concern to abuse issues and client harm to self or others, 
while sharing information pertinent to the case across team members. Following termination of the legal case, the original counseling rules of confidentiality would be reinstated. In response to that decision, two versions of the consent form were created to address each situation, and law students were routinely reminded to consider confidentiality policies before engaging counselors in their cases.

\section{Role differences}

Mental health professionals and lawyers present with myriad professional and personality differences that can impede effective collaboration (Maidenberg \& Golick, 2001). For instance, while a counselor's main role is to listen and empower clients to act, lawyers are trained to problem solve on their client's behalf (Peters, 1989). In addition, counselors tend to focus globally or holistically in considering the complexity of client struggles within a context, and they are often trained to conceptualize multilevel interventions that entail collaboration across organizations (Vera \& Speight, 2007). Conversely, a lawyer's main focus must be on legal issues, with a tendency to possess an individualistic mind frame in problem solving (Colbert et al., 1996; Peters, 1989).

Those differing approaches of each professional have, at times, created frustration for both the law students and counselors. Early on in the collaborative, the Counseling and Law Clinic directors recognized the need to educate their supervisees on their differing roles and perspectives, with ongoing reminders of those distinctions (Galowitz, 1999). To clarify counselors' roles, a handout was created and disseminated to each Law Clinic class at the beginning of each semester. The handout (provided in Appendix A) specifies counselors' possible actions in regards to the collaboration.

\section{Counselors' limitations}

Over the program's time span it became evident that student-counselors' roles somewhat differed from those suggested of social workers in the literature. Unlike fully employed and licensed mental health professionals, the counselors' time, experience, and expertise were limited by their status as students. As an example, law students in one case asked the judge if student-counselors could attest to the credibility of a client's story in court. The judge, however, deemed such evidence as questionable due to the counselors' student status. Consequently, awareness of certain student-counselor limitations has resulted in more frequent client referrals to employed professionals.

\section{Interpreters}

Challenges related to counselors' work with interpreters have been documented at length in the literature (Century, Leavey, \& Payne, 2007; Farooq \& Fear, 2003; Langdon \& Cheng, 2002), and experienced within the program itself. Problems specific to this collaborative include interpreters who became overwhelmed and unable to function in response to client trauma histories; whose limited language skills impeded effective client representation; who assumed control of sessions or failed to interpret literally, and; whose gender, nationality, or ethnic traits inhibited client disclosure. 
In response to such problems, the law and counseling faculty developed a training to impart across all involved student professionals. Although limited space prohibits a full description of competent services, essential aspects of such a training include procedural steps in preparing interpreters for a session, such as verification of the interpreter's linguistic efficacy, understanding of seating structure and eye contact procedures that facilitate the client-lawyercounselor alliance, comfort level with the profundity of the client's history, and understanding of their own and the counselor's role. After-session debriefing may entail case analysis or interventions with interpreters who assumed session control or overreacted to session content (Paone \& Malott, 2008).

\section{Discussion}

A counselor-law collaborative promotes social justice, advocacy, and multicultural counseling knowledge and skills in a unique and dynamic learning environment. It provides counseling students real world experiences with a diversity of underserved clientele, as well as crucial experience in collaborating across systems and professionals to facilitate client access to legal and basic resources. Such training is critical for increasing students' skills in interdisciplinary and cross-cultural work, as well as in applying theory and skills to social justice and advocacy practices (Bemak et al., 2011). Indeed, each semester students have provided written feedback (see Appendix B for summary examples) that indicates perceived growth in skills specific to multicultural competency, client advocacy, and collaboration with professionals. A counselor-law collaborative program could be adapted according to each unique setting.

For instance, in university settings without law schools, counselor educators could develop a collaborative program with one or more law firms in their community. Firms that espouse a social justice approach in their work would likely be most open to such ventures. As an example, in the metropolitan area in which the authors live, there exist myriad legal firms that offer low-cost legal services to marginalized populations, such as persons living in poverty, those who are homeless or at risk of losing their homes, immigrants and refugees, persons with disabilities or illnesses (such as AIDS), and domestic violence survivors. Such clients will often present with a plethora of additional, non-legal issues to which lawyers are unable to attend and to which counselors are uniquely trained to address.

Such collaborative ventures can also be adapted to meet the curricular needs of a counseling program. An interdisciplinary program can act as a stand-alone course (perhaps for multicultural counseling credit), as part of an on or off campus counselor-training clinic, or applied as a service component or service learning project embedded within a course. Specific to the classroom, a collaborative venture could be adapted to meet the educational goals of a course. For instance, students new to a counseling program may, through an orientation course, most benefit from the wealth of knowledge gained through helping clients locate basic resources as well as health and mental health services. Students within a career course can be required to offer vocational and educational counseling services to clientele. Those in a multicultural counseling course may be required to engage in an advocacy task, while those in basic skills, practicum, or internship courses could expand their clinical skills through individual client work. 


\section{Expanding the Model: Additional Collaborative Suggestions}

The general format of the interdisciplinary model described in this article could also be used to establish relationships with additional community organizations. Faculty members could collaborate with school, community, or religious agencies serving individuals who are homeless, foster care youth, substance-abusers, and alternative high school students (Bemak et al., 2011). They could work with reentry programs for clients transitioning out of the military, prisons, juvenile detention centers, or the foster care system. Other options include shelters with psychiatric patients or domestic violence survivors, as well as youth centers that serve marginalized populations such as the LGBTQ community. Organizations specific to work with refugees and immigrants include welcoming centers and centers to aid survivors of torture or other traumas. Considering the time and monetary constraints experienced by many of the above listed agencies, a proposed collaborative may be well received by many such community organizations.

\section{Feedback, Limitations, and Future Directives}

In addition to stating learning outcomes, students are asked to provide written feedback regarding any negatives experienced in program participation. Major challenges identified by the students (see Appendix B for representative statements) include excessive time commitments required for identifying client resources and difficulty managing affective reactions to client issues. From a faculty perspective, challenges to course-based service work include the additional time required in implementing service-specific training and ongoing supervision, as well as a need for flexibility and an openness, to non-traditional counselor practices. A final limitation to the current model involves client feedback. Although informal client feedback via word of mouth has indicated satisfaction with services received from the counseling students, there is currently an absence of formal client assessment.

Future directives in the development of interdisciplinary law-counselor programs should be empirical in nature, in order to determine effective training practices and client outcomes. For instance, because such ventures propose to increase counselors' skills and knowledge related to social justice advocacy and multicultural counseling, outcomes according to these pedagogical goals could be assessed in both quantitative and qualitative formats. Studies could also compare counseling students' learning outcomes to those whose social justice learning is classroom-based to determine differences in learning through the two formats. Finally, inquiry could determine, from the perspective of the client, best practice in counselor-law collaboratives.

\section{Contact information:}

Krista Malott

Department of Education and Counseling,

Villanova University,

Villanova, PA 19085

Email: krista.malott@villanova.edu 


\section{References}

Anderson, A., Barenberg, L., \& Tremblay, P. R. (2006). Lawyers' ethics in interdisciplinary collaboratives: Some answers to some persistent questions (Research Paper No. 101). Boston, MA: Boston College Law School.

Barrett, A. (2011). Multicultural social justice and human rights: Strategic professional development for social work and counseling practitioners. Journal for Social Action in Counseling and Psychology, 3, 117-123.

Retrieved from http://www.psysr.org/jsacp/barrett-v3n1-11_117-123.pdf

Bemak, F., Chung, R. C-Y, Talleyrand, R. M., Jones, H., \& Daquin, J. (2011). Implementing multicultural social justice strategies in counselor education training programs. Journal for Social Action in Counseling and Psychology, 3, 1-43. Retrieved from http://www.psysr.org/jsacp/brubaker-v3n1-11_44-58.pdf

Bernard, J. L. (1997). The discrimination model. In C. E. Watkins, Handbook of psychotherapy supervision (pp. 310-327). NY: Wiley

Blustein, D. L. (2006). The psychology of working: A new perspective for career development, counseling, and public policy. Mahwah, NJ: Erlbaum.

Borders, L. D., \& Brown, L. L. (2005). The new handbook of counseling supervision. Mahwah, NJ: Lahaska Press.

Brubaker, M. D., Puig, A., Reese, R. F., \& Young, J. (2010). Integrating social justice into counseling theories pedagogy: A case example. Counselor Education \& Supervision, 50, 88-102.

Century, G., Leavey, G., \& Payne, H. (2007). The experience of working with refugees: Counsellors in primary care. British Journal of Guidance \& Counselling, 35, 23-40. doi: $10.1080 / 03069880601106765$

Chang, C. Y., Crethar, H. C., \& Ratts, M. J. (2010). Social justice: A national imperative for counselor education and supervision. Counselor Education and Supervision, 50, 82-87.

Chung, R. C-Y., Bemak, F., \& Grabosky, T. K. (2011). Multicultural-social justice leadership strategies: Counseling and advocacy with immigrants. Journal for Social Action, 3, 86102. Retrieved from www.psysr.org/jsacp/chung-v3n1-11_86-102.pdf

Colbert, D. L., O'Sullivan, J. L., Leviton, S. P.,Weimer, D. J., Herr, S. S., Deise, J. E., Reese, A. P., \& Milleman, M. A. (1996). Ethical decision making and ethics instruction in clinical law practice. Clinical Law Review, 3, 109-174. 
Counselors for Social Justice (CSJ) Ethics Committee (2011). The Counselors for Social Justice (CSJ) Code of Ethics. Journal for Social Action in Counseling and Psychology, 3, 1-21. Retrieved from http://www.psysr.org/jsacp/Ibrahim-v3n2_1-21.pdf

D'Andrea, M., \& Heckman, E. F. (2008). Contributing to the ongoing evolution of the multicultural counseling movement: An introduction to the special issue. Journal of Counseling \& Development, 86, 259-260.

Dixon, A. L., Tucker, C., \& Clark, M. A. (2010). Integrating social justice advocacy with national standards of practice: Implications for school counselor education. Counselor Education and Supervision, 50, 103-115.

Eyler, J., Giles, D. E., \& Schmiede, A. (1996). A practitioner's guide to reflection in servicelearning: Student voices and reflection. Nashville, TN: Project funded by the Corporation for National Service.

Farooq, S., \& Fear, C. (2003). Working through interpreters. Advances in Psychiatric Treatment, 9, 104-109. doi: 10.1192/apt.01.12

Furco, A., \& Billig, S. H. (Eds.). (2002). Service-learning: The essence of the pedagogy. Greenwich, CT: Information Age Publishing.

Galowitz, P. (1999). Collaboration between lawyers and social workers: Re-examining the nature and potential of the relationship. Fordham Law Review, 675), 2123-2154.

Glosoff, H. L., \& Durham, J. C. (2010). Using supervision to prepare social justice counseling advocates. Counselor Education \& Supervision, 50, 116-129.

Godźiak, E. M. (2004). Training refugee mental health providers: Ethnography as a bridge to multicultural practice. Human Organization, 63, 203-210. doi: 0018-7259/04/0202-03-08

Golick, T., \& Lessem, J. (2004). A law and social work clinical program for the elderly and disabled: Past and future challenges. Journal of Law \& Policy, 14, 183-208.

Green, E. J., McCollum, V. C., \& Hays, D. G. (2008). Teaching advocacy counseling within a social justice framework: Implications for school counseling. Journal for Social Action in Counseling and Psychology, 1, 14-30. Retrieved from http://www.psysr.org/jsacp/GreenV1N2-08.pdf

Hitchcock, J. (2002). Lifting the white veil: An exploration of White American culture in a multiracial context. Roselle, NJ: Crandall, Dostie \& Douglass Books.

Langdon, H. W., \& Cheng, L. L. (2002). Collaborating with interpreters and translators: A guide for communication disorders professionals. Eau Clair, WI: Thinking Publications. 
Lattuca, L. R. (2002). Learning interdisciplinarity: Sociocultural perspectives on academic work. Journal of Higher Education, 73, 711-739. doi: 10.1353/jhe.2002.0054

Lee, C. C. (Ed.). (2007). Counseling for social justice (2 ${ }^{\text {nd }}$ ed.). Alexandria, VA: American Counseling Association.

Lewis, J. A., Arnold, M. S., House, R., \& Toporek, R. L. (2003). ACA Advocacy Competencies. Retrieved from http://www.counseling.org/Publications/

Lewis, J. A., Ratts, M. J., Paladino, D. A., \& Toporek, R. L. (2011). Social justice counseling and advocacy: Developing new leadership roles and competencies. Journal for Social Action in Counseling and Psychology, 3, 5-16. Retrieved from psysr.org.

Maidenberg, M., \& Golick, T. (2001). Developing or enhancing interdisciplinary programs: A model for teaching collaboration. Professional Development, 4, 15-24. Retrieved from http://www.profdevjournal.org/articles/42015.pdf

Murray, C. E., Pope, A. L., \& Rowell, P. C. (2010). Promoting counseling students' advocacy competencies through service-learning. Journal for Social Action in Counseling and Psychology, 2, 29-47. Retrieved from psysr.org.

Nilsson, J. E., Schale, C. L., \& Khamphakdy-Brown, S. (2011). Facilitating trainees' multicultural development and social justice advocacy through a refugee/ immigrant mental health program. Journal of Counseling \& Development, 89, 413-422.

Paone, T. R., \& Malott, K. M. (2008).Using interpreters in mental health counseling: A literature review and recommendations. Journal of Multicultural Counseling and Development, 36, 130-142.

Peters, J. K. (1989). Concrete strategies for managing ethically-based conflicts between children's lawyers and consulting social workers who serve the same client. Children's Legal Rights Journal, 10, 15-28.

Prendes-Lintel, M. (2001). A working model in counseling recent refugees. In J. G. Ponterotto, J. M. Casas, L. A. Suzuki, C. M. Alexander (Eds.), Handbook of Multicultural Counseling ( ${ }^{\text {nd }}$ ed., pp. 729-752). Thousand Oaks, CA: Sage.

Ratts, M. J., \& Wood, C. (2011). The fierce urgency of now: Diffusion of innovation as a mechanism to integrate social justice in counselor education. Counselor Education \& Supervision, 50, 207-223.

Ratts, M. J., DeKruyf, L., \& Chen-Hayes, S. F. (2007). The ACA advocacy competencies: A social justice advocacy framework for professional school counselors. Professional School Counseling, 11, 90-97.

Ratts, M. J., Toporek, R. L., \& Lewis, J. A. (Eds.). (2010). ACA Advocacy Competencies: A social justice framework for counselors. Alexandria, VA: American Counseling Association. 
Smith, E. J. (2006). The strength-based counseling model. The Counseling Psychologist, 34, 1379. doi: $10.1177 / 0011000005277018$

Speight, S. L., \& Vera, E. M. (2004). A social justice agenda: Ready, or not? Counseling Psychologist, 32, 109-118. doi: 10.1177=0011000003260005

Talleyrand, R. M., Chung, R. C-Y., \& Bemak, F. (2006). Incorporating social justice in counselor training programs. In R. L. Toporek, L. H. Gerstein, N. A. Fouad, G. Roysircar, \& T. Israel (Eds.), Handbook for social justice in counseling psychology (pp. 44-58). Thousand Oaks, CA: Sage.

Vera, E. M., \& Speight, S. L. (2007). Advocacy, outreach, and prevention: Integration social action roles in professional training. In E. Aldarondo (Ed.), Advancing justice through clinical practice (pp. 373-416). Mahwah, NJ: Erlbaum.

Wright, J. L. (2005). Therapeutic jurisprudence in an interprofessional practice at the University of St. Thomas interprofessional center for counseling and legal services (Research Paper No. 05-12). St. Thomas Law Review, 17, 501-513.

Zalaquett, C. P., Foley, P. F., Tillotson, K., Dinsmore, J. A., \& Hof, D. (2008). Multicultural and social justice training for counselor education programs and colleges of education: Rewards and challenges. Journal of Counseling and Development, 86, 323-329. 


\section{Appendix A}

\section{Law-Counselor Collaborative: Program Description for Lawyers}

What is the Law-Counselor Collaborative? Counselors, language interpreters, and lawyers work as a team, drawing upon unique skills and perspectives, to aid clients.

What is Counseling? Master-level mental health counselors address clients' basic, health, and mental health needs. A counselor's principal job is to listen, a key aspect of stress relief/healing. At times, counselors may seek to empower clients to advocate for themselves, or they may provide specific skills, referrals or resources to address client barriers and expand their support systems.

\section{Examples of counselor tasks in a legal context:}

- Provide basic counseling for clients

- Impart coping techniques for client stress or trauma

- Limited educational and career counseling

- Refer clients to long-term counseling

- Prepare clients for court in collaboration with law students

- Identify basic resources (e.g., food, housing, clothing)

- Impart skills and resources for clients new to the country

- Support for law students regarding: client trauma, consult regarding broaching difficult subjects or trauma histories, and information regarding client issues

\section{Three models of service provision:}

1) Team collaboration. Counseling and law students work closely together, occasionally meeting as a team, with and without the client, and with regular updates.

2) Separate service provision. Counseling students independently address client needs. Law students are regularly notified of counselor's actions.

3) Post case. After legal representation is terminated, the counselors work independently with clients. Case progress will be reported to directors only.

Introducing counselors: Persons of many cultures perceive counseling as taboo or, if they have experienced trauma, may initially be fearful/suspicious of any new professional brought onto the case. Hence, counselors can be introduced with, and as, members of the law team whose job it is to listen and connect clients with desired supports or resources.

Confidentiality: Counselors and lawyers are bound by different confidentiality rules. We must report cases of elder abuse, threats to client or others (suicidal, homicidal), and child abuse. The client will be informed of this through a consent form. With the client's permission, issues potentially important to the case will be shared with the lawyers.

Referral process: Complete a referral form obtained from the legal administrator and have it approved by your clinic director. The administrator will fax it to the counseling supervisor. You will promptly be contacted by a counseling student to discuss case details and determine which model of service provision (described above) applies. 


\section{Appendix B}

\section{Gains and Challenges: Student-Counselor Representative/Thematic Quotes}

\begin{tabular}{|c|c|c|}
\hline & & Student-Counselor Representative Statement(s) \\
\hline \multirow{3}{*}{$\begin{array}{l}\text { Counselors' } \\
\text { Skills or } \\
\text { Knowledge } \\
\text { Gained }\end{array}$} & $\begin{array}{l}\text { Multicultural } \\
\text { Counseling } \\
\text { Awareness, } \\
\text { Skills, and } \\
\text { Knowledge }\end{array}$ & $\begin{array}{l}\text { "Through this experience I was reminded that each of us looks at our lives } \\
\text { and situations through unique lenses, and while some may be similar, } \\
\text { others may be dramatically different." } \\
\text { "I have expanded my ability to be empathetic towards individuals different } \\
\text { from myself." } \\
\text { "I have a newfound sensitivity for immigrants and refugees, I can better } \\
\text { understand the obstacles they face and can actually feel their frustration } \\
\text { after trying to obtain resources through the same channels they will have } \\
\text { to." } \\
\text { "I learned ... to constantly be aware of my biases when working with } \\
\text { clients. I could read as many articles as I can and examine my beliefs, } \\
\text { biases ... but without putting any of that into practice by working with } \\
\text { someone who is from a different culture, it wouldn't have been enough." }\end{array}$ \\
\hline & $\begin{array}{c}\text { Social Justice } \\
\text { Advocacy } \\
\text { Skills }\end{array}$ & $\begin{array}{l}\text { "I gained greater experience in how to empower those who represent } \\
\text { underserved populations by helping them to reach self-sufficiency and } \\
\text { have greater access to basic resources." } \\
\text { "The most important knowledge and skills I gained in working with clients } \\
\text { from different cultures and SES ... is how to best draw on the clients' own } \\
\text { resources, what they bring with them from their backgrounds, how to best } \\
\text { capitalize or utilize their strengths." } \\
\text { "I learned the importance of empowering my clients," and "I learned why } \\
\text { I need to advocate for my clients in order that their basic needs were } \\
\text { guaranteed." }\end{array}$ \\
\hline & $\begin{array}{c}\text { Collaborative } \\
\text { Knowledge } \\
\text { and Skills }\end{array}$ & $\begin{array}{l}\text { "The practical experience of working with interpreters has been helpful." } \\
\text { "Working as a team with the other counseling students, law students and } \\
\text { Law School staff has been the most valuable aspect of participating in the } \\
\text { program." } \\
\text { "I have been able to work as a team with other counselors to gain best } \\
\text { practices and different techniques to use in order to be more successful } \\
\text { with clients." }\end{array}$ \\
\hline \multirow[t]{2}{*}{ Challenges } & $\begin{array}{l}\text { Managing } \\
\text { Personal } \\
\text { Reactions }\end{array}$ & $\begin{array}{l}\text { "Internalizing a lot of the issues that arose with the clients was the } \\
\text { hardest thing for me." }\end{array}$ \\
\hline & $\begin{array}{c}\text { Time } \\
\text { Requirement }\end{array}$ & $\begin{array}{l}\text { "Some tasks [counselor's] will face are very time consuming and meeting } \\
\text { with clients can take up the majority of a day." }\end{array}$ \\
\hline
\end{tabular}

